\title{
Exporting China's Successes in Vaccine Preventable Hepatitis
}

\author{
Lance E. Rodewald ${ }^{1, \pm}$
}

Almost four decades of science, innovation, and programmatic effort to control and prevent vaccinepreventable viral hepatitis have paid off spectacularly well in China. In the pre-vaccine era, nearly $10 \%$ of children were infected by hepatitis B virus (HBV) especially during childbirth - causing them to be lifelong carriers of HBV, able to infect others, and in great danger of liver cancer and cirrhosis as adults (1). Most young children were infected by hepatitis A virus (HAV), with a lifetime infection rate of $90 \%$, keeping this virus in circulation and causing outbreaks among older children and adults who could become quite ill from hepatitis A (2).

Fast-forward to the present day, and the landscape is markedly changed for the better. The current generation of children in China is the first generation to be almost completely free of hepatitis $\mathrm{B}$ and protected for life (3); the incidence of hepatitis A is extremely low in China as vaccine-induced immunity has replaced infection-induced immunity among children; and a third viral hepatitis - hepatitis E - is now preventable by vaccines developed and licensed in China (4).

Vaccines can take partial credit for these successes since they could not have been achieved without vaccines, but the vaccines were deployed in the context of a strategic strengthening of maternal and child health and childbirth practices - for hepatitis B prevention - and improvements in sanitation - for hepatitis A and hepatitis E prevention. Integration of vaccination and health system and sanitation improvement was not only essential for control of these infections, but also brought benefits beyond viral hepatitis prevention and control. For example, China was an early participant in the United Nations International Children's Fund (UNICEF)-coordinated Safe Motherhood Initiative that improved childbirth practices in many countries around the world (5). Bringing childbirth into birthing centers and hospitals in China not only made childbirth safer, preventing potentially deadly post-partum hemorrhage and significantly reducing the maternal mortality rate, but also provided an effective platform for administration of a timely birth dose of hepatitis B vaccine to the newborn infant. More hygienic birthing practices also enabled elimination of maternal-neonatal tetanus - a major accomplishment that was verified in 2012 by the World Health Organization (WHO) (6).

There is critically important remaining work for prevention and control of these three vaccine preventable diseases (VPDs) in China. Most importantly, the nearly 90 million individuals living with HBV infection, who were born before hepatitis B vaccine was widely available in China, are in need of identification and clinical management to prevent progression to cirrhosis, liver cancer, and premature death (7). Although there has been a $97 \%$ reduction in maternal-to-child transmission of $\mathrm{HBV}$, there are an estimated 50,000 breakthrough chronic infections of newborn infants every year (3), which necessitates tightening the program and providing antivirals during pregnancy for certain HBV carriers to prevent transmission during childbirth. The rapid decline in the incidence of hepatitis A following introduction of hepatitis A vaccine in 2007 resulted in many children born in the years immediately prior to the vaccine's introduction to be neither infected nor vaccinated allowing a gap in population immunity among 10 -to20 -year-olds in China that leaves some people susceptible to HAV infection (2). The public health significance of this immunity gap is yet to be determined but will be important to understand and possibly act upon. Finally, because there is insufficient experience with the relatively new hepatitis $\mathrm{E}$ vaccine, the roles of the hepatitis $E$ vaccine in outbreak responses and routine immunization have not been fully determined (8). Although Hepatitis E vaccine is eligible for $\mathrm{WHO}$ prequalification, it has not yet been submitted for prequalification, limiting its use overseas and depriving much of the world of this prevention tool.

Even though there is much work to be done, China has clearly traveled a great distance in the prevention and control of vaccine preventable hepatitis. China's comprehensive approaches to the prevention and control of hepatitis B and hepatitis A can serve as 
evidence-based models for countries that are at earlier points in this journey. For example, many countries have yet to embrace the timely birth dose of hepatitis B vaccine to prevent perinatal hepatitis $B$ infection. Ninety percent of perinatal infections become chronic infections that cause direct suffering and perpetuate HBV transmission. Although the WHO recommends the birth dose for all newborn infants, only $11 \%$ of the WHO African Region's newborn infants receive the timely birth dose (9). Hepatitis B vaccine could become an added-value pillar to strengthen and improve maternal child health. As another example, countries that have been highly endemic for hepatitis A may be able to look to the experience in China of introducing hepatitis A vaccine in the context of improvements in sanitation practices. A domesticallydeveloped inactivated hepatitis A vaccine was prequalified by WHO in 2017 and is contributing to the global vaccine supply for immunization programs $(10)$.

Chinese scientists and health professionals have worked with the WHO, UNICEF, and other countries for many years to support viral hepatitis prevention and control - including serving on advisory committees, supporting epidemiological studies, and providing vaccines. Indeed, a characteristic of China's effort to control and prevent viral hepatitis has been longstanding collaborations with international organizations such as the WHO, UNICEF, Gavi the Global Alliance on Vaccines and Immunization, and US CDC.

But now is a good time for accelerating China's global support for hepatitis prevention and control. The WHO has a health sector strategy to eliminate viral hepatitis as a public health problem by 2030 (11). China CDC could become a WHO Collaborating Center for Viral Hepatitis, supporting the WHO effort with experience, expertise, and vaccines. As a WHO Collaborating Center, the number of opportunities to contribute to the elimination of viral hepatitis will greatly increase. In a bit of good timing, Gavi recently approved support of the hepatitis B birth dose and will begin investing in the birth dose in Gavi-eligible countries in 2021 (12). China's comprehensive approach to hepatitis B prevention through strengthening the maternal health system could be highly relevant in many Gavi-eligible countries. Viral hepatitis prevention and control could become a focus of the Belt and Road Initiative on health, which includes many Gavi-eligible countries. In short, exporting China's successes on prevention and control of vaccine preventable hepatitis can and will make the world a healthier and safer place for all.

doi: $10.46234 / \mathrm{ccdcw} 2020.153$

\# Corresponding author: Lance E. Rodewald, rodewaldl@chinacdc.cn.

${ }^{1}$ National Immunization Program, Chinese Center for Disease Control and Prevention, Beijing, China.

Submitted: July 19, 2020; Accepted: July 22, 2020

\section{REFERENCES}

1. Liang XF, Bi SL, Yang WZ, Yang WZ, Wang LD, Cui G, et al. Evaluation of the impact of Hepatitis $B$ vaccination among children born during 1992-2005 in China. J Infect Dis 2009;200(1):39 - 47. http://dx.doi.org/10.1086/599332.

2. Wang FZ, Sun XJ, Wang F, Zheng H, Jia ZY, Zhang GM, et al. Changing epidemiology of Hepatitis A in China: evidence from three national serological surveys and the National Notifiable Disease Reporting System. Hepatology 2020. http://dx.doi.org/10.1002/hep. 31429.

3. Cui FQ, Shen LP, Li L, Wang HQ, Wang FZ, Bi SL, et al. Prevention of chronic Hepatitis B after 3 decades of escalating vaccination policy, China. Emerg Infect Dis 2017;23(5):765 - 72. http://dx.doi.org/10. 3201/eid2305.161477.

4. Zhu FC, Zhang J, Zhang XF, Zhou C, Wang ZZ, Huang SJ, et al. Efficacy and safety of a recombinant hepatitis $\mathrm{E}$ vaccine in healthy adults: a large-scale, randomised, double-blind placebo-controlled, phase 3 trial. Lancet 2010;376(9744):895 - 902. http://dx.doi.org/10. 1016/S0140-6736(10)61030-6.

5. Liu XN, Yan H, Wang DL. The evaluation of pSafe Motherhoodq program on maternal care utilization in rural western China: a difference in difference approach. BMC Public Health 2010;10:566. http://dx.doi.org/10.1186/1471-2458-10-566.

6. World Health Organization. China eliminates maternal and neonatal tetanus. https://www.who.int/westernpacific/news/detail/30-11-2012china-eliminates-maternal-and-neonatal-tetanus. [2020-07-19].

7. Nayagam S, Chan PL, Zhao K, Sicuri E, Wang XC, Jia JD, et al. Investment Case for a Comprehensive Package of Interventions Against Hepatitis B in China: Applied Modeling to Help National Strategy Planning. Clin Infect Dis 2020; ciaa134. https://doi.org/10.1093/ $\mathrm{cid} / \mathrm{ciaa} 134$.

8. World Health Organization. Hepatitis E vaccine: WHO position paper, May 2015. Wkly Epidemiol Rec 2015;90(18):185-200. https://www. who.int/wer/2015/wer9018/en/.

9. Li X, Dumolard L, Patel M, Gacic-Dobo M, Hennessey K. Implementation of hepatitis B birth dose vaccination - worldwide, 2016. Wkly Epidemiol Rec 2018;93(7):61-72. https://apps.who.int/ iris/bitstream/handle/10665/260207/WER9307.pdf;sequence=1.

10. World Health Organization. List of prequalified vaccines. https:// extranet.who.int/gavi/PQ_Web/. [2020-07-20].

11. World Health Organization. Global Health Sector strategy on viral hepatitis 2016-2021. https://apps.who.int/iris/bitstream/handle/10665/ 246177/WHO-HIV-2016.06-eng.pdf;sequence=1. [2020-07-19].

12. Gavi. Vaccine investment strategy. https://www.gavi.org/our-alliance/ strategy/vaccine-investment-strategy. [2020-07-19]. 